American Journal of Biostatistics 1 (1): 46-61, 2010

ISSN 1948-9889

(C) 2010 Science Publications

\title{
Testing the Equality of Growth Curves of Independent Populations with Application on Egypt Case
}

\author{
${ }^{1}$ Hanan Girgis, ${ }^{2}$ Ramadan Hamed and ${ }^{3}$ Magued Osman \\ ${ }^{1}$ Department of Evidence-Based Population Policy Project, \\ Egyptian Cabinet Information and Decision Support Center, 164 Nile St., Agouza, Giza, Egypt \\ ${ }^{2}$ Department of Statistics, Faculty of Economics and Political Science, Cairo University, Egypt \\ ${ }^{3}$ Department of Statistics, Faculty of Economics and Political Science, Cairo University and Chairman, \\ Egyptian Cabinet Information and Decision Support Center, Egypt
}

\begin{abstract}
Problem statement: Numerous trials have been conducted to compare the body growth curves and hence growth rates relying on smoothing and modeling different growth curves using different parameter values for the same model. This study aimed to construct a test of the equality of two percentile growth curves and of a set of percentile growth curves from two independent populations regardless of the shape of these curves. Currently available tests allow us to make a decision on one group. Making a decision regarding the whole curve necessitates building new tests. Approach: This study developed two tests of the equality of two growth curves based on the concept of the precedence and the chi-square tests and a test of the equality of a set of growth curves. The Monte Carlo simulation technique was used to investigate the power of the three tests under a shift in the location parameter and under a shift in the scale parameter of the normal and gamma distributions. The tests were applied to the weight-for-age percentile growth curves of Egyptian regions. Results: The curve precedence test is more powerful than the curve chi-square test in testing the equality of growth curves under a shift in the location parameter of both the normal and gamma distributions. It is also more powerful than the curve chi-square test in testing the equality of growth curves under a shift in the scale parameter of the gamma distribution and in testing equality of growth curves with high ranks under a shift in the scale parameter of the normal distribution. Applying the new tests to the weight-for-age growth curves of the two Egyptian regions showed that the regions have different growth curves. Conclusion: The new tests are powerful in testing the equality of growth curves. According to them, the two Egyptian regions have different nutritional status.
\end{abstract}

Key words: Curve precedence test, curve chi-square test, curves set chi-square test, anthropometric measures, percentile curves

\section{INTRODUCTION}

The percentile growth curve is a tool for presenting the status of different groups (such as age and height) in a population with respect to a certain phenomenon or index. Percentiles reflect the position of the individual's observed value in relation to the values of the other individuals of a particular group in terms of percentage of the values equaled or exceeded (Matthews et al., 2000). Empirical percentiles can be calculated for each group and plotted on a graph at the midpoint of each group. The plotted points of each percentile are then connected to form the percentile curve.

Growth curves can be obtained using percentiles values or z-score values (Dibley et al., 1987a). This study focuses on testing the equality of percentile growth curves.

Growth curves were first obtained to monitor and evaluate population or individual growth rates and patterns using anthropometric indicators. They can be used in a variety of fields -e.g., health-to monitor population growth and improvements in these fields. In general, population or individual growth curves could be useful in (Dibley et al., 1987b):

- Describing the status of the population

- Identifying individuals and groups that should be targeted by interventions

- Determining and monitoring cases of very low or very high value regarding the phenomenon under

Corresponding Author: Hanan Girgis, Department of Evidence-Based Population Policy Project,

Egyptian Cabinet Information and Decision Support Center, 164 Nile St., Agouza, Giza, Egypt

Tel.: 202-33140020 Fax: 202-27941222 
study in a certain population by comparing the population growth curves to "ideal" growth curves

- Assessing the impact of different interventions on the phenomenon under study by comparing growth curves at different points in time

The comparison of growth curves of different independent populations is a frequently encountered problem, especially in pediatric fields. Looking at the growth curves of different populations is not enough to decide whether they are significantly different. To make such decisions, the equality of the two curves should first be tested. Many trials have been made to compare not only the body growth curves and hence growth rates, of humans but also the growth curves of animals. These trials have relied on smoothing and modeling the different growth curves using different parameter values of the same model. The parameter values of these models are then used to compare the curves.

The main limitations of this approach are the following:

- Handling, smoothing and fitting the appropriate model for the curve is time consuming and effort intensive

- Applying the same model to the different curves, even with different parameter values, could prove difficult or impossible

- The predicted values of the curve points rather than the actual values are used in smoothing and modeling to compare curves, leading to lack of precision in the results obtained

This study aimed to construct a test of the equality of percentile growth curves. Many nonparametric tests were reviewed to identify an appropriate test. However, the findings showed that currently available tests only allow us to make a decision on one group (e.g., age group). To make a decision regarding the whole curve that reflects the values of several groups, a new test needed to be built. The objectives of this study can be summed up as follows:

- To construct tests of the equality of two percentile growth curves as well as the equality of two sets of growth curves from two independent populations regardless of the shape of these curves (i.e., applying the tests will not necessitate fitting a mathematical model for the curves)

- To investigate the performance of the tests by studying the power properties of the tests under different distributions

- To construct the weight-for-age growth curves of Egypt and of two regions of Egypt, namely Urban
Governorates and Lower Egypt and Upper Egypt and Frontier Governorates and to apply the tests to the two regions

\section{MATERIALS AND METHODS}

This study presents a new test, the curve precedence test, based on the concept of the precedence test, in order to test the equality of two growth curves of two independent populations. To evaluate the performance of the precedence test, another test based on the concept of the chi-square test, curve chi-square test, is presented and the power of the precedence test is compared to the power of this test. The chi-square test was also adapted to test the equality of two sets of growth curves. The Monte-Carlo simulation technique was used to investigate the power properties of the curve chi-square test, the curve precedence test and the adapted chi-square test-referred to as the "curves set chi-square test", or "CS" chi-square test. The simulation aimed at revealing the following aspects:

- The effect of the different distributions on the power of the three tests

- The effect of the sample size on the power of the three tests

- The values of the shift at which each of the three tests has high powers

- The effect of the rank of the percentile on the power of the curve precedence test and curve chisquare test

The power was tested for curves with three age groups. For the curve chi-square test and the curve precedence test, the power was estimated for the 10th percentile curve and the 75 th percentile curve. For the curves set "CS" chi-square test, the power was estimated for a set consisting of the 10th percentile curve, the 50th percentile curve and the 90th percentile curve.

The three tests were applied to the most frequently used percentile weight-for-age growth curves of children less than 5 years, namely the 5th, 10th, 25th, 50th, 75th, 90th and 95th percentile curves of Egyptian regions. For the purposes of these tests, Egypt was divided into two regions: Region 1, which includes urban governorates and Lower Egypt and Region 2, which includes Upper Egypt and frontier governorates. The percentile weight-for-age growth curves of children aged less than five in the two regions was obtained and the equality of each pair of growth curves as well as the equality of the two sets of curves was tested. 
Curve precedence test: The curve precedence test is a test of the equality of two growth curves of two independent populations based on the concept of the precedence test. The precedence test is a nonparametric test used in quality control to test whether the lifetime distributions of two independent samples are the same. As stated in (Balakrishnan and Tony $\mathrm{Ng}, 2006$ ), the precedence test was first established by Nelson in 1963 and many studies have since proposed alternatives to the test. Precedence-type test is preferred in quality control studies when the units under the test are expensive, as these tests do not require that one wait until all units under the test fail.

In the case of the two samples X's and Y's, the precedence test is based on the number of X's exceeding or preceding a certain quantile of the Y's distribution. The test statistic $\mathrm{p}_{(\mathrm{r})}$ is defined as the number of values in the $\mathrm{X}$-sample less than or equal to the $\mathrm{r}^{\text {th }}$ order statistic of the Y-sample under the null hypothesis $\mathrm{H}_{0}$ (Balakrishnan and Tony $\mathrm{Ng}, 2006$ ).

For each group, the null hypothesis is:

$$
\mathrm{H}_{0}: \mathrm{F}_{\mathrm{X}}=\mathrm{F}_{\mathrm{Y}}
$$

Where:

$\mathrm{F}_{\mathrm{X}}=$ The cdf of the X's

$F_{Y}=$ The cdf of the Y's

$$
\operatorname{pr}\left(p_{(r[i])}=j \mid H_{0}: F_{X}=F_{Y}\right)=\frac{\left(\begin{array}{c}
j+r-1 \\
j
\end{array}\right)\left(\begin{array}{c}
n_{1}+n_{2}-j-r \\
n_{1}-j
\end{array}\right)}{\left(\begin{array}{c}
n_{1}+n_{2} \\
n_{2}
\end{array}\right)}
$$

Where:

$\mathrm{j}=$ An integer $\leq \mathrm{n}_{1}$

$\mathrm{n}_{1}=$ The $\mathrm{X}$-sample size

$\mathrm{n}_{2}=$ The $\mathrm{Y}$-sample size

The precedence test in its current form could be used to test whether the values of a percentile of a certain group-for example infants aged 12-14 months-in two populations are equal. In this case, the two samples are: Infants aged 12-14 months in population 1 and infants aged 12-14 months in population 2. The test allows us to make a decision regarding one age group. The test needed to be modified to allow us to make a decision concerning a whole curve that consists of multiple groups.

Using the curve precedence test to test the equality of two growth curves, the null hypothesis of the curve is rejected if the summation of the precedence test statistics of the $\mathrm{L}$ groups exceeds a critical value.

Desu and Raghavarao (2004) stated that, in the case of large samples, the distribution of $\mathrm{Z}$, expressed as:
$\mathrm{Z}=\frac{\mathrm{p}_{(\mathrm{r})}-\mathrm{E}\left(\mathrm{p}_{(\mathrm{r})} \mid \mathrm{H}_{0}\right)}{\sqrt{\operatorname{var}\left(\mathrm{p}_{(\mathrm{r})} \mid \mathrm{H}_{0}\right)}}$

"can be approximated by the standard normal distribution and this approximation can be used to find approximations to the critical values and the P-values."

Theorem 1 (Ashour and Salem, 2005): If $X_{i}$ 's are independent normal variables with mean 0 and unit variance, $i=1,2, \ldots, L$, then $\sum_{i=1}^{L} X_{i}^{2}$ has chi-square distribution with $\mathrm{L}$ degrees of freedom.

Using the previous theorem, where $\mathrm{L}$ is the number of the groups, for the $\mathrm{r}^{\text {th }}$ percentile curve:

$\mathrm{V}_{\mathrm{r}}=\sum_{\mathrm{i}=1}^{\mathrm{L}}\left(\frac{\mathrm{p}_{(\mathrm{r}[\mathrm{i}])}-\mathrm{E}\left(\mathrm{p}_{(\mathrm{r}[\mathrm{i}]} \mid \mathrm{H}_{0}\right)}{\sqrt{\operatorname{var}\left(\mathrm{p}_{(\mathrm{r}[\mathrm{i}])} \mid \mathrm{H}_{0}\right)}}\right)^{2}$

$V_{r}$ has chi-square distribution with $L$ degrees of freedom.

Curve chi-square test: The curve chi-square test is a test of the equality of two percentile curves from two independent populations using the chi-square test. For each group, the test is built on combining the samples of the two populations in one sample (the combined sample). For a certain percentile curve, the percentile value is calculated for the combined sample of each group. The two populations are considered to have equal percentile curves if the observations of the combined sample in each group that are less than or equal to the percentile value of the group are divided between the two samples in the same proportion with which the whole combined sample of the group is divided between the two samples.

Figure 1 presents an illustrative example of the curve chi-square test in a group. The example in Fig. 1 shows that the observations that are less than or equal to the 20th percentile of the combined sample are divided between the two samples in a different proportion than the observations of the whole sample.

For each group, the expected number of observations less than or equal to a certain percentile in the $\mathrm{i}^{\text {th }}$ sample, $\mathrm{i}=1,2, \ldots, \mathrm{k}$, (here $\mathrm{k}=2$ ) should be equal to the probability that an observation in the combined sample of this group belongs to the $i^{\text {th }}$ sample multiplied by the number of observations of the combined sample of the group less than or equal the percentile value. If the expected number of one of the two samples is very different from the observed number, then the two samples do not have equal percentiles. 
Am. J. Biostatistics 1 (1): 46-61, 2010

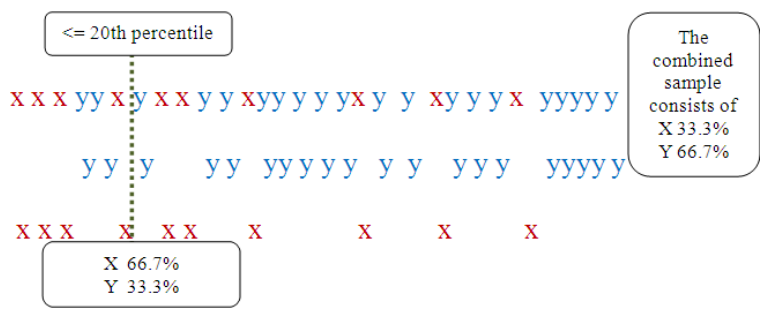

Fig. 1: Illustrative example of the curve chi-square test in one group

In a certain group, the expected number of observations of a certain percentile curve of the combined sample that belong to one of the two samples has a binomial distribution with parameters $n, p_{j}$.

Let $\mathrm{p}_{\mathrm{ji}}$ be the probability that an observation in the combined sample of group $\mathrm{j}$ belongs to the $\mathrm{i}^{\text {th }}$ sample, $\mathrm{j}=1,2, \ldots, \mathrm{L}, \mathrm{i}=1,2, \mathrm{X}_{\mathrm{ji}}$ be the number of observations of the combined sample of group $\mathrm{j}$ less than or equal the percentile value that belong to the $\mathrm{i}^{\text {th }}$ sample, $j=1,2, \ldots, L, i=1,2$ and $n_{j}$ be the number of observations of the combined sample of group $\mathrm{j}$ less than or equal the percentile value, $j=1,2, \ldots, \mathrm{L}$ :

$$
\begin{aligned}
& \sum_{\mathrm{i}=1}^{\mathrm{k}} \mathrm{p}_{\mathrm{ji}}=1 \\
& \sum_{\mathrm{i}=1}^{\mathrm{k}} \mathrm{x}_{\mathrm{ji}}=\mathrm{n}_{\mathrm{j}}
\end{aligned}
$$

The expected number of observations of group $\mathrm{j}$ less than or equal the percentile value in the $i^{\text {th }}$ sample is $\mathrm{E}\left(\mathrm{X}_{\mathrm{ji}}\right)$, where:

$$
E\left(X_{j i}\right)=n_{j} p_{j i}
$$

The discrepancy of the observed number from the expected number is reflected through the squared difference of the observed number from the expected number and is divided by the expected number to put the discrepancies of the different samples and the different groups on equal footing.

Let $\mathrm{V}_{\mathrm{j}}$ reflect the discrepancies of the observed numbers from the expected numbers in group $\mathrm{j}$, $\mathrm{j}=1,2, \ldots, \mathrm{L}:$

$$
\mathrm{V}_{\mathrm{j}}=\sum_{\mathrm{i}=1}^{\mathrm{k}} \frac{\left(\left(\mathrm{x}_{\mathrm{ji}}-\mathrm{E}\left(\mathrm{X}_{\mathrm{ji}}\right)\right)^{2}\right.}{\mathrm{E}\left(\mathrm{X}_{\mathrm{ji}}\right)}
$$

$\mathrm{V}_{\mathrm{j}}$ has chi-square distribution with $\mathrm{k}_{\mathrm{j}}-1$ degrees of freedom (Kapur and Saxena, 2007).
In our case:

$$
\text { Since } \mathrm{k}_{\mathrm{j}}=2 \text {, then } \mathrm{k}_{\mathrm{j}}-1=1
$$

$\mathrm{V}_{\mathrm{j}}$ has chi-square distribution with 1 degree of freedom.

Theorem 2 (Ashour and Salem, 2005): If $X_{1}, X_{2}, \ldots$, $\mathrm{X}_{\mathrm{L}}$ are independent random variables having chisquare distribution with $\mathrm{k}_{1}, \mathrm{k}_{2}, \ldots, \mathrm{k}_{\mathrm{L}}$ degrees of freedom, then $\mathrm{Y}=\sum_{\mathrm{i}=1}^{\mathrm{L}} \mathrm{X}_{\mathrm{i}}$ has chi-square distribution with $\mathrm{k}=\sum_{\mathrm{i}=1}^{\mathrm{L}} \mathrm{k}_{\mathrm{i}}$ degrees of freedom.

The summation of the discrepancies in the $\mathrm{L}$ groups $\sum_{\mathrm{j}=1}^{\mathrm{L}} \mathrm{V}_{\mathrm{j}}$ will have chi-square distribution with $\mathrm{L}$ degrees of freedom.

Curves set chi-square test: The curves set test is a test of the equality of two sets of percentile growth curves of two independent populations using the $\chi^{2}$ test. Each population has a set of percentile curves, with each curve representing a certain percentile curve. The samples of the two populations are combined and the percentiles of the combined sample are determined.

Let $y_{u j}$ be the value of the $u^{\text {th }}$ percentile of the combined sample of group $\mathrm{j}, \mathrm{o}_{\mathrm{uji}}$ be the number of the observations of the $i^{\text {th }}$ sample of group $j$ greater than $\mathrm{y}_{(\mathrm{u}-1) \mathrm{j}}$ and less than or equal $\mathrm{y}_{\mathrm{uj}}$ and $\mathrm{e}_{\mathrm{uji}}$ be the expected number of observations of the $i^{\text {th }}$ sample of group $j$ greater than $\mathrm{y}_{(\mathrm{u}-1) \mathrm{j}}$ and less than or equal $\mathrm{y}_{\mathrm{uj}}$ :

$$
\mathrm{V}=\sum_{\mathrm{u}=1}^{\mathrm{S}} \sum_{\mathrm{j}=1}^{\mathrm{L}} \sum_{\mathrm{i}=1}^{\mathrm{k}} \frac{\left(\left(\mathrm{o}_{\mathrm{uji}}-\mathrm{e}_{\mathrm{ujj}}\right)^{2}\right.}{\mathrm{e}_{\mathrm{uji}}}
$$

has chi-square distribution with $\mathrm{S} \times \mathrm{L}$ degrees of freedom.

If any of the successive percentiles of the same group are equal, the degrees of freedom are decreased by the number of empty categories.

Table 1 shows the design of the chi-square curves set test statistic calculations.

Distributions used for the simulation: The powers of the tests were estimated in the case of symmetric distributions applying to the normal distribution and in the case of skewed distributions applying to the gamma distribution.

The normal distribution and Gamma distribution, among many other distributions, were fitted for the Egypt Demographic and Health Survey (EDHS) weight-for-age data for three age groups: 1-4 months, 5-8 months and 9-12 months using "EasyFit 5.1 Professional". 
Am. J. Biostatistics 1 (1): 46-61, 2010

Table 1: Design of the table of curves set chi-square test statistic calculations

\begin{tabular}{|c|c|c|c|c|c|}
\hline & & $\left(\leq \mathrm{y}_{1}\right)$ & $\left(>y_{1}-\leq y_{2}\right)$ & $\left(>y_{2}-\leq y_{3}\right)$ & $\left(>y_{s-1}-\leq y_{s}\right)$ \\
\hline \multirow[t]{4}{*}{$\overline{\mathrm{G}_{1}}$} & Sample 1 & $\mathrm{o}_{111}$ & $\mathrm{O}_{211}$ & $\mathrm{O}_{311}$ & $\mathrm{o}_{\mathrm{S} 11}$ \\
\hline & & $e_{111}$ & $e_{211}$ & $e_{311}$ & $\mathrm{e}_{\mathrm{S} 11}$ \\
\hline & Sample 2 & $\mathrm{o}_{112}$ & $\mathrm{O}_{212}$ & $\mathrm{O}_{312}$ & $\mathrm{o}_{\mathrm{S} 12}$ \\
\hline & & $\mathrm{e}_{112}$ & $\mathrm{eO}_{212}$ & $e_{312}$ & $\mathrm{e}_{\mathrm{s} 12}$ \\
\hline \multicolumn{6}{|l|}{. } \\
\hline \multirow[t]{5}{*}{$\mathrm{G}_{\mathrm{L}}$} & Sample 1 & $\mathrm{o}_{1 \mathrm{~L} 1}$ & & & $\mathrm{o}_{\mathrm{SL} 1}$ \\
\hline & & $\mathrm{e}_{\mathrm{IL} 1}$ & & & $\mathrm{e}_{\mathrm{SL}}$ \\
\hline & & & & & 1 \\
\hline & Sample 2 & $\mathrm{o}_{1 \mathrm{~L} 2}$ & & & $\mathrm{O}_{\mathrm{SL} 2}$ \\
\hline & & $\mathrm{e}_{1 \mathrm{~L} 2}$ & & & $\mathrm{e}_{\mathrm{SL} 2}$ \\
\hline
\end{tabular}

The power was then investigated under the shift in the location parameter as well as under the shift in the scale parameter of each of the two distributions.

Implementation of the Simulation: The power was tested for each parameter under the shift " $k$ " for different values of $\mathrm{k}$ where:

$\mathrm{H}_{0}: \mathrm{F}_{\mathrm{x}}(\mathrm{x}, \theta)=\mathrm{F}_{\mathrm{y}}(\mathrm{x},(\mathrm{k}+1) \theta)$ ag. $\mathrm{H}_{1}: \mathrm{F}_{\mathrm{x}}(\mathrm{x}, \theta) \neq \mathrm{F}_{\mathrm{y}}(\mathrm{x},(\mathrm{k}+1) \theta)$

The power was also tested for different sample sizes $\left(\mathrm{n}_{1}, \mathrm{n}_{2}\right)$ where:

$\mathrm{n}_{1}=$ The size of the $\mathrm{X}$ sample

$\mathrm{n}_{2}=$ The size of the Y sample

The power was tested for the following combinations of sample sizes:

- $\mathrm{n}_{1}=50, \mathrm{n}_{2}=50$

- $\mathrm{n}_{1}=100, \mathrm{n}_{2}=100$

- $\mathrm{n}_{1}=500, \mathrm{n}_{2}=500$

- $\mathrm{n}_{1}=100, \mathrm{n}_{2}=50$

- $\mathrm{n}_{1}=100, \mathrm{n}_{2}=80$

Number of runs " $\mathrm{R}$ " was calculated as follows:

$$
\mathrm{R}=\frac{(1-\mathrm{p})}{\mathrm{p}(\mathrm{cv})^{2}}
$$

Where:

$\mathrm{p}=$ The level of significance

$\mathrm{cv}=$ The coefficient of variation

Under a $20 \%$ coefficient of variation and 0.05 level of significance, $\mathrm{R}=475$.

Under a $15 \%$ coefficient of variation and 0.05 level of significance, $\mathrm{R}=844$.

The simulation was implemented with $\mathrm{R}=500$ and $\mathrm{R}=1000$.
The power was tested under the shift in the location parameter as well as under the shift in the scale parameter through Monte Carlo simulations using "MATLAB R2007b". A program was developed for each of the three tests to: (a) generate a random sample for each of the three age groups from each fitted distribution, the normal distribution and the Gamma distribution with the fitted values of the parameters and (b) calculate the test statistic value. The programs were then tested manually to ensure their correctness.

For each run, SPSS 16 was used to compare the test statistic value of the sample with the tabulated values of chi-square $(\alpha=0.05)$ and to calculate the power of the test.

Application: Testing the equality of weight-for-age growth curves of Egyptian regions: Anthropometric indices are obtained for use in assessing nutritional status, health status and the impact of health interventions. The most widely used anthropometric indices are weight-for-height, height-for-age and weight-for-age. In this study, the weight-for-age growth curves of children less than 5 years in Egyptian regions were obtained and the three tests applied to them. The tests were applied to the most frequently used percentile growth curves, namely the 5th, 10th, 25th, 50th, 75th, 90th and 95th percentile curves. For the purposes of these tests, Egypt was divided into two regions: Region 1: Urban Governorates and Lower Egypt and Region 2: Upper Egypt and Frontier Governorates. The percentile weight-for-age growth curves of children of the two regions aged less than five were obtained and the equality of each pair of growth curves as well as the equality of the two sets of curves were tested.

The section on child health in the EDHS includes data about child's birth weight, current weight, current height (length/stature) and current age. Age and weight data are used to obtain weight-for-age curves for Egypt. The different cycles of the survey were conducted using the same methodologies and the data collected using the same definitions.

Before developing growth charts, age data had to be grouped, with each group containing 400-500 observations to achieve precision of the empirical percentiles at the specific age groups (Kuczmarski et al., 2002). In order to have a sufficient number of observations, EDHS 2000, EDHS 2003 and EDHS 2005 data were pooled.

Pooling the data of the three cycles could be accepted since:

- The time period of the three cycles was not too long, thus the population could not experience a natural change in its anthropometric standards 
Am. J. Biostatistics 1 (1): 46-61, 2010

- No nutrition or health interventions that could affect the population's anthropometric standards were applied in Egypt during that period

- The data of the three cycles were collected using the same definitions and methodologies

Children were grouped by age as follows:

- Infants aged 1-11 months were grouped by single month

- Infants aged 12-23 months were grouped by 3month interval

- Children aged 24-59 months were grouped by 6month interval

The 5th, 10th, 25th, 50th, 75th, 90th and 95th percentiles of each age group in Egypt and in each of the two regions were calculated to construct the growth curves.

For the curve precedence test and the curve chisquare test, the hypotheses were as follows:

$\mathrm{H}_{0}$ : Region 1 and Region 2 have the same $\mathrm{r}^{\text {th }}$ percentile curve

Against:

$\mathrm{H}_{1}$ : Region 1 and Region 2 do not have the same $\mathrm{r}^{\text {th }}$ percentile curve

For the curves set chi-square test, the hypotheses were as follows:

$\mathrm{H}_{0}$ : The set of growth curves of Region 1 and Region 2 are equal

\section{Against:}

$\mathrm{H}_{1}$ : The set of growth curves of Region 1 and Region 2 are not equal

\section{RESULTS AND DISCUSSION}

\section{Power of the three tests:}

Distribution used for the simulation: Goodness of fit results were better in the case of the Gamma distribution than in the case of the normal distribution. Nevertheless, the powers of the tests were investigated under the normal distribution as well since this is used very frequently.

Table 2 shows the parameter estimates for the normal and Gamma distributions.
Table 2: Fitted parameters of the normal and gamma distributions

\begin{tabular}{|c|c|c|c|c|}
\hline \multirow[b]{2}{*}{ Distribution } & \multirow[b]{2}{*}{ Parameter } & \multicolumn{3}{|c|}{ Age group } \\
\hline & & $1-4$ & $5-8$ & $9-12$ \\
\hline \multirow[t]{2}{*}{ Normal } & $\hat{\mu}$ & 5.499 & 7.542 & 8.930 \\
\hline & $\hat{\sigma}$ & 1.365 & 1.351 & 1.376 \\
\hline \multirow[t]{2}{*}{ Gamma } & $\hat{\alpha}$ & 16.228 & 31.152 & 42.120 \\
\hline & $\hat{\beta}$ & 0.339 & 0.242 & 0.212 \\
\hline
\end{tabular}

Simulation results under the shift in the location parameter: Table 3 shows the power of the three tests under the shift in the normal distribution location parameter, while Table 4 shows the power of the three tests under the shift in the Gamma distribution location parameter.

The power estimation through Monte Carlo simulation for $\alpha=0.05$ shows the following:

- The power of the three tests increases with increasing sample sizes

- The power of the three tests increases with increasing values of the shift " $\mathrm{k}$ "

- The power reaches 1 with a shift that ranges from 0.1 , in the case of $\mathrm{n}_{1}=\mathrm{n}_{2}=500$, to 0.25 , in the case of $\mathrm{n}_{1}=\mathrm{n}_{2}=50$

- The difference in the sizes of the two samples tested against each other does not affect the power value

- The power with $\mathrm{R}=1000$ shows slight differences from the power with $R=500$

- The power of the curve chi-square test and the curve precedence test is higher in the case of the 10th percentile curve than in the case of the 75th percentile curve

- A comparison of the power of the curve chi-square test and the curve precedence test reveals that the curve precedence test performs better than the curve chi-square test

- The power differs slightly between normal distribution and Gamma distribution in the case of the 10th percentile curve. The difference is higher in the case of the 75th percentile curve, with higher power for normal distribution

- The power of the curves set chi-square test is higher than the power of the curve chi-square test, especially for relatively large shifts $(k \geq 0.1)$

- The power of the 10th percentile curve precedence test is higher than the power of the curves set chisquare test. In the case of relatively large sample sizes, $\left(\mathrm{n}_{1}=100, \mathrm{n}_{2}=80\right),\left(\mathrm{n}_{1}=\mathrm{n}_{2}=100\right),\left(\mathrm{n}_{1}=\mathrm{n}_{2}=\right.$ 500 ), under the normal distribution, the power of the 75th percentile curve precedence test is also higher than the power of the curves set chi-square test 
Am. J. Biostatistics 1 (1): 46-61, 2010

Table 3: Power of the three tests under the shift in the normal distribution location parameter

\begin{tabular}{|c|c|c|c|c|c|c|c|c|}
\hline \multirow[b]{2}{*}{$\mathrm{R}$} & \multirow[b]{2}{*}{$\mathrm{n}_{1}$} & \multirow[b]{2}{*}{$\mathrm{n}_{2}$} & \multirow[b]{2}{*}{$\mathrm{K}$} & \multicolumn{2}{|c|}{ Curve precedence test } & \multicolumn{2}{|c|}{ Curve chi-square test } & \multirow{2}{*}{$\begin{array}{l}\text { CS Chi-Square } \\
\text { test }\end{array}$} \\
\hline & & & & 10th percentile & 75th percentile & 10th percentile & 75th percentile & \\
\hline \multirow[t]{20}{*}{500} & 50 & 50 & 0.05 & 0.288 & 0.054 & 0.116 & 0.000 & 0.054 \\
\hline & & & 0.10 & 0.792 & 0.448 & 0.512 & 0.026 & 0.504 \\
\hline & & & 0.15 & 0.978 & 0.902 & 0.872 & 0.248 & 0.962 \\
\hline & & & 0.20 & 1.000 & 1.000 & 0.986 & 0.818 & 1.000 \\
\hline & & & 0.25 & 1.000 & 1.000 & 1.000 & 0.994 & 1.000 \\
\hline & 100 & 100 & 0.05 & 0.456 & 0.252 & 0.248 & 0.002 & 0.188 \\
\hline & & & 0.10 & 0.972 & 0.936 & 0.878 & 0.274 & 0.930 \\
\hline & & & 0.15 & 1.000 & 1.000 & 0.998 & 0.944 & 1.000 \\
\hline & & & 0.20 & 1.000 & 1.000 & 1.000 & 1.000 & 1.000 \\
\hline & 500 & 500 & 0.05 & 0.968 & 0.994 & 0.968 & 0.504 & 0.978 \\
\hline & & & 0.10 & 1.000 & 1.000 & 1.000 & 1.000 & 1.000 \\
\hline & 100 & 50 & 0.05 & 0.366 & 0.114 & 0.110 & 0.000 & 0.050 \\
\hline & & & 0.10 & 0.852 & 0.670 & 0.514 & 0.104 & 0.594 \\
\hline & & & 0.15 & 0.998 & 0.984 & 0.886 & 0.786 & 0.990 \\
\hline & & & 0.20 & 1.000 & 1.000 & 0.996 & 0.996 & 1.000 \\
\hline & & & 0.25 & 1.000 & 1.000 & 1.000 & 1.000 & 1.000 \\
\hline & 100 & 80 & 0.05 & 0.406 & 0.214 & 0.208 & 0.000 & 0.124 \\
\hline & & & 0.10 & 0.950 & 0.908 & 0.798 & 0.210 & 0.856 \\
\hline & & & 0.15 & 1.000 & 1.000 & 0.992 & 0.912 & 1.000 \\
\hline & & & 0.20 & 1.000 & 1.000 & 1.000 & 1.000 & 1.000 \\
\hline \multirow[t]{20}{*}{1000} & 50 & 50 & 0.05 & 0.290 & 0.058 & 0.127 & 0.000 & 0.065 \\
\hline & & & 0.10 & 0.775 & 0.462 & 0.481 & 0.012 & 0.488 \\
\hline & & & 0.15 & 0.978 & 0.921 & 0.861 & 0.279 & 0.946 \\
\hline & & & 0.20 & 1.000 & 1.000 & 0.990 & 0.800 & 0.999 \\
\hline & & & 0.25 & 1.000 & 1.000 & 1.000 & 0.990 & 1.000 \\
\hline & 100 & 100 & 0.05 & 0.440 & 0.273 & 0.281 & 0.002 & 0.195 \\
\hline & & & 0.10 & 0.961 & 0.947 & 0.875 & 0.241 & 0.930 \\
\hline & & & 0.15 & 1.000 & 1.000 & 0.996 & 0.951 & 1.000 \\
\hline & & & 0.20 & 1.000 & 1.000 & 1.000 & 1.000 & 1.000 \\
\hline & 500 & 500 & 0.05 & 0.968 & 0.994 & 0.952 & 0.491 & 0.980 \\
\hline & & & 0.10 & 1.000 & 1.000 & 1.000 & 1.000 & 1.000 \\
\hline & 100 & 50 & 0.05 & 0.348 & 0.114 & 0.097 & 0.001 & 0.070 \\
\hline & & & 0.10 & 0.862 & 0.692 & 0.470 & 0.117 & 0.609 \\
\hline & & & 0.15 & 0.993 & 0.991 & 0.898 & 0.801 & 0.979 \\
\hline & & & 0.20 & 1.000 & 1.000 & 0.986 & 0.991 & 1.000 \\
\hline & & & 0.25 & 1.000 & 1.000 & 1.000 & 1.000 & 1.000 \\
\hline & 100 & 80 & 0.05 & 0.382 & 0.200 & 0.186 & 0.002 & 0.165 \\
\hline & & & 0.10 & 0.920 & 0.899 & 0.772 & 0.227 & 0.841 \\
\hline & & & 0.15 & 1.000 & 1.000 & 0.991 & 0.939 & 0.999 \\
\hline & & & 0.20 & 1.000 & 1.000 & 1.000 & 1.000 & 1.000 \\
\hline
\end{tabular}

Table 4: Power of the three tests under the shift in the gamma distribution location parameter

\begin{tabular}{|c|c|c|c|c|c|c|c|c|}
\hline \multirow[b]{2}{*}{$\mathrm{R}$} & \multirow[b]{2}{*}{$\mathrm{n}_{1}$} & \multirow[b]{2}{*}{$\mathrm{n}_{2}$} & \multirow[b]{2}{*}{$\mathrm{K}$} & \multicolumn{2}{|c|}{ Curve precedence test } & \multicolumn{2}{|c|}{ Curve chi-square test } & \multirow[b]{2}{*}{ CS Chi-Square test } \\
\hline & & & & 10th percentile & 75th percentile & 10th percentile & 75th percentile & \\
\hline \multirow[t]{20}{*}{500} & 50 & 50 & 0.05 & 0.288 & 0.052 & 0.120 & 0.000 & 0.068 \\
\hline & & & 0.10 & 0.790 & 0.380 & 0.518 & 0.014 & 0.530 \\
\hline & & & 0.15 & 0.978 & 0.858 & 0.892 & 0.192 & 0.942 \\
\hline & & & 0.20 & 1.000 & 0.990 & 0.990 & 0.690 & 1.000 \\
\hline & & & 0.25 & 1.000 & 1.000 & 1.000 & 0.964 & 1.000 \\
\hline & 100 & 100 & 0.05 & 0.446 & 0.242 & 0.292 & 0.000 & 0.232 \\
\hline & & & 0.10 & 0.974 & 0.910 & 0.888 & 0.198 & 0.920 \\
\hline & & & 0.15 & 1.000 & 1.000 & 0.996 & 0.922 & 1.000 \\
\hline & & & 0.20 & 1.000 & 1.000 & 1.000 & 1.000 & 1.000 \\
\hline & 500 & 500 & 0.05 & 0.970 & 0.992 & 0.962 & 0.450 & 0.988 \\
\hline & & & 0.10 & 1.000 & 1.000 & 1.000 & 1.000 & 1.000 \\
\hline & 100 & 50 & 0.05 & 0.362 & 0.098 & 0.074 & 0.000 & 0.088 \\
\hline & & & 0.10 & 0.860 & 0.616 & 0.508 & 0.098 & 0.624 \\
\hline & & & 0.15 & 0.996 & 0.984 & 0.892 & 0.686 & 0.968 \\
\hline & & & 0.20 & 1.000 & 1.000 & 0.998 & 0.990 & 0.998 \\
\hline & & & 0.25 & 1.000 & 1.000 & 1.000 & 1.000 & 1.000 \\
\hline & 100 & 80 & 0.05 & 0.412 & 0.182 & 0.242 & 0.000 & 0.162 \\
\hline & & & 0.10 & 0.920 & 0.860 & 0.808 & 0.178 & 0.850 \\
\hline & & & 0.15 & 1.000 & 1.000 & 0.996 & 0.862 & 1.000 \\
\hline & & & 0.20 & 1.000 & 1.000 & 1.000 & 1.000 & 1.000 \\
\hline \multirow[t]{5}{*}{1000} & 50 & 50 & 0.05 & 0.312 & 0.061 & 0.132 & 0.000 & 0.078 \\
\hline & & & 0.10 & 0.801 & 0.385 & 0.520 & 0.009 & 0.499 \\
\hline & & & 0.15 & 0.989 & 0.866 & 0.896 & 0.203 & 0.938 \\
\hline & & & 0.20 & 0.999 & 0.992 & 0.987 & 0.721 & 1.000 \\
\hline & & & 0.25 & 1.000 & 1.000 & 1.000 & 0.967 & 1.000 \\
\hline
\end{tabular}


Am. J. Biostatistics 1 (1): 46-61, 2010

Table 4: Continued

\begin{tabular}{|c|c|c|c|c|c|c|c|}
\hline \multirow{4}{*}{100} & 100 & 0.05 & 0.448 & 0.238 & 0.298 & 0.002 & 0.224 \\
\hline & & 0.10 & 0.972 & 0.901 & 0.866 & 0.195 & 0.919 \\
\hline & & 0.15 & 1.000 & 1.000 & 0.999 & 0.890 & 1.000 \\
\hline & & 0.20 & 1.000 & 1.000 & 1.000 & 0.999 & 1.000 \\
\hline \multirow[t]{2}{*}{500} & 500 & 0.05 & 0.975 & 0.995 & 0.967 & 0.463 & 0.981 \\
\hline & & 0.10 & 1.000 & 1.000 & 1.000 & 1.000 & 1.000 \\
\hline \multirow[t]{5}{*}{100} & 50 & 0.05 & 0.374 & 0.100 & 0.096 & 0.001 & 0.095 \\
\hline & & 0.10 & 0.877 & 0.671 & 0.518 & 0.087 & 0.606 \\
\hline & & 0.15 & 0.999 & 0.980 & 0.887 & 0.694 & 0.980 \\
\hline & & 0.20 & 1.000 & 1.000 & 0.992 & 0.989 & 1.000 \\
\hline & & 0.25 & 1.000 & 1.000 & 1.000 & 1.000 & 1.000 \\
\hline \multirow[t]{4}{*}{100} & 80 & 0.05 & 0.407 & 0.195 & 0.243 & 0.001 & 0.157 \\
\hline & & 0.10 & 0.930 & 0.846 & 0.800 & 0.161 & 0.855 \\
\hline & & 0.15 & 1.000 & 0.999 & 0.988 & 0.866 & 1.000 \\
\hline & & 0.20 & 1.000 & 1.000 & 1.000 & 0.999 & 1.000 \\
\hline
\end{tabular}

Table 5: Power of the three tests under the shift in the normal distribution scale parameter

\begin{tabular}{|c|c|c|c|c|c|c|c|c|}
\hline \multirow[b]{2}{*}{$\mathrm{R}$} & \multirow[b]{2}{*}{$\mathrm{n}_{1}$} & \multirow[b]{2}{*}{$\mathrm{n}_{2}$} & \multirow[b]{2}{*}{$\mathrm{K}$} & \multicolumn{2}{|c|}{ Curve precedence test } & \multicolumn{2}{|c|}{ Curve chi-square test } & \multirow[b]{2}{*}{ CS Chi-Square test } \\
\hline & & & & 10th percentile & 75th percentile & 10th percentile & 75th percentile & \\
\hline \multirow{24}{*}{500} & \multirow[t]{5}{*}{50} & \multirow[t]{5}{*}{50} & 0.25 & 0.012 & 0.052 & 0.138 & 0.000 & 0.066 \\
\hline & & & 0.50 & 0.002 & 0.206 & 0.444 & 0.000 & 0.342 \\
\hline & & & 0.75 & 0.000 & 0.458 & 0.784 & 0.000 & 0.714 \\
\hline & & & 1.00 & 0.000 & 0.710 & 0.942 & 0.010 & 0.922 \\
\hline & & & 1.50 & 0.000 & 0.938 & 0.996 & 0.072 & 0.998 \\
\hline & \multirow[t]{5}{*}{100} & \multirow[t]{5}{*}{100} & 0.25 & 0.054 & 0.124 & 0.276 & 0.000 & 0.176 \\
\hline & & & 0.50 & 0.522 & 0.486 & 0.858 & 0.002 & 0.786 \\
\hline & & & 0.75 & 0.912 & 0.778 & 0.992 & 0.016 & 0.988 \\
\hline & & & 1.00 & 0.992 & 0.964 & 1.000 & 0.092 & 1.000 \\
\hline & & & 1.50 & 1.000 & 1.000 & 1.000 & 0.436 & 1.000 \\
\hline & \multirow[t]{4}{*}{500} & \multirow[t]{4}{*}{500} & 0.25 & 0.944 & 0.664 & 0.968 & 0.004 & 0.980 \\
\hline & & & 0.50 & 1.000 & 0.998 & 1.000 & 0.498 & 1.000 \\
\hline & & & 0.75 & 1.000 & 1.000 & 1.000 & 0.976 & 1.000 \\
\hline & & & 1.00 & 1.000 & 1.000 & 1.000 & 1.000 & 1.000 \\
\hline & \multirow[t]{5}{*}{100} & \multirow[t]{5}{*}{50} & 0.25 & 0.008 & 0.104 & 0.218 & 0.000 & 0.118 \\
\hline & & & 0.50 & 0.060 & 0.314 & 0.644 & 0.002 & 0.566 \\
\hline & & & 0.75 & 0.330 & 0.626 & 0.924 & 0.004 & 0.916 \\
\hline & & & 1.00 & 0.606 & 0.862 & 0.992 & 0.022 & 0.990 \\
\hline & & & 1.50 & 0.936 & 0.976 & 1.000 & 0.102 & 1.000 \\
\hline & \multirow[t]{5}{*}{100} & \multirow[t]{5}{*}{80} & 0.25 & 0.046 & 0.116 & 0.302 & 0.000 & 0.116 \\
\hline & & & 0.50 & 0.360 & 0.416 & 0.812 & 0.000 & 0.710 \\
\hline & & & 0.75 & 0.824 & 0.786 & 0.984 & 0.016 & 0.980 \\
\hline & & & 1.00 & 0.970 & 0.940 & 0.996 & 0.048 & 1.000 \\
\hline & & & 1.50 & 1.000 & 1.000 & 1.000 & 0.298 & 1.000 \\
\hline \multirow[t]{24}{*}{1000} & \multirow[t]{5}{*}{50} & 50 & 0.25 & 0.012 & 0.055 & 0.127 & 0.000 & 0.058 \\
\hline & & & 0.50 & 0.002 & 0.190 & 0.445 & 0.000 & 0.322 \\
\hline & & & 0.75 & 0.000 & 0.437 & 0.797 & 0.002 & 0.713 \\
\hline & & & 1.00 & 0.003 & 0.706 & 0.939 & 0.004 & 0.933 \\
\hline & & & 1.50 & 0.000 & 0.932 & 0.997 & 0.041 & 0.996 \\
\hline & 100 & 100 & 0.25 & 0.064 & 0.123 & 0.324 & 0.000 & 0.165 \\
\hline & & & 0.50 & 0.509 & 0.474 & 0.843 & 0.002 & 0.802 \\
\hline & & & 0.75 & 0.917 & 0.838 & 0.983 & 0.022 & 0.986 \\
\hline & & & 1.00 & 0.995 & 0.995 & 1.000 & 0.117 & 1.000 \\
\hline & & & 1.50 & 1.000 & 1.000 & 1.000 & 0.454 & 1.000 \\
\hline & 500 & 500 & 0.25 & 0.956 & 0.683 & 0.960 & 0.015 & 0.968 \\
\hline & & & 0.50 & 1.000 & 0.999 & 1.000 & 0.517 & 1.000 \\
\hline & & & 0.75 & 1.000 & 1.000 & 1.000 & 0.978 & 1.000 \\
\hline & & & 1.00 & 1.000 & 1.000 & 1.000 & 0.999 & 1.000 \\
\hline & 100 & 50 & 0.25 & 0.013 & 0.062 & 0.217 & 0.000 & 0.113 \\
\hline & & & 0.50 & 0.071 & 0.308 & 0.675 & 0.000 & 0.544 \\
\hline & & & 0.75 & 0.308 & 0.627 & 0.930 & 0.004 & 0.909 \\
\hline & & & 1.00 & 0.641 & 0.857 & 0.983 & 0.025 & 0.994 \\
\hline & & & 1.50 & 0.928 & 0.972 & 1.000 & 0.102 & 1.000 \\
\hline & 100 & 80 & 0.25 & 0.035 & 0.109 & 0.274 & 0.000 & 0.158 \\
\hline & & & 0.50 & 0.374 & 0.417 & 0.788 & 0.002 & 0.744 \\
\hline & & & 0.75 & 0.839 & 0.757 & 0.978 & 0.016 & 0.977 \\
\hline & & & 1.00 & 0.975 & 0.939 & 0.999 & 0.060 & 1.000 \\
\hline & & & 1.50 & 1.000 & 1.000 & 1.000 & 0.319 & 1.000 \\
\hline
\end{tabular}


Am. J. Biostatistics 1 (1): 46-61, 2010

Table 6: Power of the three tests under the shift in the gamma distribution scale parameter

\begin{tabular}{|c|c|c|c|c|c|c|c|c|}
\hline \multirow[b]{2}{*}{$\mathrm{R}$} & \multirow[b]{2}{*}{$\mathrm{n}_{1}$} & \multirow[b]{2}{*}{$\mathrm{n}_{2}$} & \multirow[b]{2}{*}{$\mathrm{K}$} & \multicolumn{2}{|c|}{ Curve precedence test } & \multicolumn{2}{|c|}{ Curve chi-square test } & \multirow[b]{2}{*}{ CS Chi-Square test } \\
\hline & & & & 10th percentile & 75 th percentile & 10th percentile & 75th percentile & \\
\hline \multirow[t]{20}{*}{500} & 50 & 50 & 0.05 & 0.236 & 0.066 & 0.090 & 0.000 & 0.060 \\
\hline & & & 0.10 & 0.678 & 0.446 & 0.350 & 0.012 & 0.392 \\
\hline & & & 0.15 & 0.938 & 0.916 & 0.744 & 0.274 & 0.902 \\
\hline & & & 0.20 & 0.992 & 0.994 & 0.940 & 0.708 & 0.988 \\
\hline & & & 0.25 & 1.000 & 1.000 & 0.994 & 0.976 & 1.000 \\
\hline & 100 & 100 & 0.05 & 0.416 & 0.280 & 0.212 & 0.002 & 0.170 \\
\hline & & & 0.10 & 0.924 & 0.954 & 0.752 & 0.204 & 0.872 \\
\hline & & & 0.15 & 1.000 & 1.000 & 0.976 & 0.922 & 0.996 \\
\hline & & & 0.20 & 1.000 & 1.000 & 1.000 & 0.998 & 1.000 \\
\hline & 500 & 500 & 0.05 & 0.958 & 0.994 & 0.912 & 0.546 & 0.966 \\
\hline & & & 0.10 & 1.000 & 1.000 & 1.000 & 1.000 & 1.000 \\
\hline & 100 & 50 & 0.05 & 0.280 & 0.080 & 0.068 & 0.000 & 0.064 \\
\hline & & & 0.10 & 0.766 & 0.722 & 0.348 & 0.094 & 0.500 \\
\hline & & & 0.15 & 0.982 & 0.990 & 0.718 & 0.718 & 0.926 \\
\hline & & & 0.20 & 1.000 & 1.000 & 0.920 & 0.988 & 0.998 \\
\hline & & & 0.25 & 1.000 & 1.000 & 0.990 & 1.000 & 1.000 \\
\hline & 100 & 80 & 0.05 & 0.400 & 0.246 & 0.186 & 0.004 & 0.108 \\
\hline & & & 0.10 & 0.872 & 0.904 & 0.656 & 0.158 & 0.788 \\
\hline & & & 0.15 & 0.994 & 1.000 & 0.958 & 0.898 & 0.996 \\
\hline & & & 0.20 & 1.000 & 1.000 & 0.998 & 1.000 & 1.000 \\
\hline \multirow[t]{20}{*}{1000} & 50 & 50 & 0.05 & 0.266 & 0.072 & 0.094 & 0.000 & 0.063 \\
\hline & & & 0.10 & 0.690 & 0.462 & 0.365 & 0.018 & 0.402 \\
\hline & & & 0.15 & 0.946 & 0.888 & 0.749 & 0.238 & 0.886 \\
\hline & & & 0.20 & 0.999 & 0.990 & 0.932 & 0.752 & 0.996 \\
\hline & & & 0.25 & 1.000 & 1.000 & 0.993 & 0.966 & 1.000 \\
\hline & 100 & 100 & 0.05 & 0.376 & 0.271 & 0.215 & 0.002 & 0.170 \\
\hline & & & 0.10 & 0.910 & 0.940 & 0.759 & 0.245 & 0.855 \\
\hline & & & 0.15 & 0.998 & 1.000 & 0.978 & 0.920 & 0.999 \\
\hline & & & 0.20 & 1.000 & 1.000 & 1.000 & 1.000 & 1.000 \\
\hline & 500 & 500 & 0.05 & 0.941 & 0.993 & 0.904 & 0.554 & 0.957 \\
\hline & & & 0.10 & 1.000 & 1.000 & 1.000 & 1.000 & 1.000 \\
\hline & 100 & 50 & 0.05 & 0.308 & 0.124 & 0.070 & 0.002 & 0.068 \\
\hline & & & 0.10 & 0.778 & 0.728 & 0.357 & 0.083 & 0.493 \\
\hline & & & 0.15 & 0.975 & 0.980 & 0.728 & 0.686 & 0.912 \\
\hline & & & 0.20 & 0.998 & 1.000 & 0.939 & 0.995 & 1.000 \\
\hline & & & 0.25 & 1.000 & 1.000 & 0.992 & 1.000 & 1.000 \\
\hline & 100 & 80 & 0.05 & 0.346 & 0.221 & 0.160 & 0.001 & 0.130 \\
\hline & & & 0.10 & 0.865 & 0.878 & 0.638 & 0.180 & 0.746 \\
\hline & & & 0.15 & 0.995 & 0.998 & 0.957 & 0.870 & 0.997 \\
\hline & & & 0.20 & 1.000 & 1.000 & 0.999 & 1.000 & 1.000 \\
\hline
\end{tabular}

Simulation results under the shift in the scale parameter: Table 5 shows the power of the three tests under the shift in the normal distribution scale parameter, while Table 6 shows the power of the three tests under the shift in the Gamma distribution scale parameter.

The estimation of the power through Monte Carlo simulation for $\alpha=0.05$ shows the following:

- The power of the three tests increases with increasing sample sizes

- The power of the three tests increases with increasing values of the shift " $\mathrm{k}$ "

- In the case of the normal distribution, the three tests are less sensitive to shifts in the scale parameter than shifts in the location parameter. High power values require higher shift values than in the case of both the normal distribution location parameter and the Gamma distribution scale parameter. Thus, under the normal distribution, the tests are more powerful in the case of the shift in location parameter than the shift in scale parameter

- $\quad$ The power with $\mathrm{R}=1000$ shows slight differences from the power with $\mathrm{R}=500$

- Under the normal distribution, the curve chi-square test is more powerful in testing the 10th percentile curve than in testing the 75th percentile curve, while the curve precedence test is less powerful in testing the 10th percentile curve than in testing the 75 th percentile curve 
- Under the Gamma distribution, the power of the curve chi-square test is higher in the case of the 10th percentile curve than in the case of the 75th percentile curve. Although the power of the curve precedence test is higher in the case of the 10th percentile curve than in the case of the 75th percentile curve for low values of " $\mathrm{k}$ ", it is higher in the case of the 75th percentile curve than in the case of the 10th percentile curve for higher values of " $k$ "
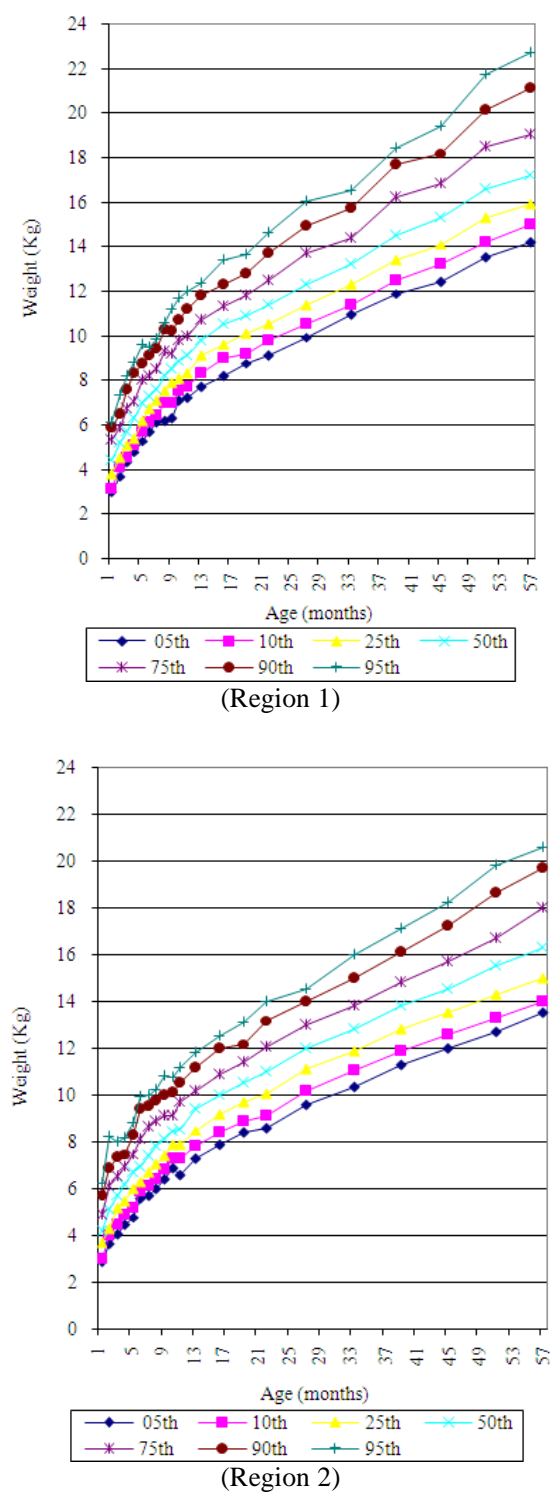

Fig. 2: Percentile growth curves for Regions 1 and 2 (Region 1): Urban governorates and lower Egypt (Region 2): Upper Egypt and frontier governorates
- A comparison of the power of the curve precedence test and the curve chi-square test reveals that under the normal distribution the curve precedence test is more powerful than the curve chi-square test in the case of the 75th percentile, while it is less powerful than the curve chi-square test in the case of the 10th percentile curve. Under the Gamma distribution, on the other hand, the curve precedence test is more powerful than the curve chi-square test in testing both the $10^{\text {th }}$ percentile and the 75th percentile curve

Testing the equality of weight-for-age growth curves of Egyptian regions: The percentile growth curves of the two Egyptian regions, namely Region 1: Urban Governorates and Lower Egypt and Region 2: Upper Egypt and Frontier Governorates, are presented in Fig. 2. The 5th, 10th, 25th, 50th, 75th, 90th and 95th percentile curves for Egypt and the two regions are presented in Fig. 3-9.

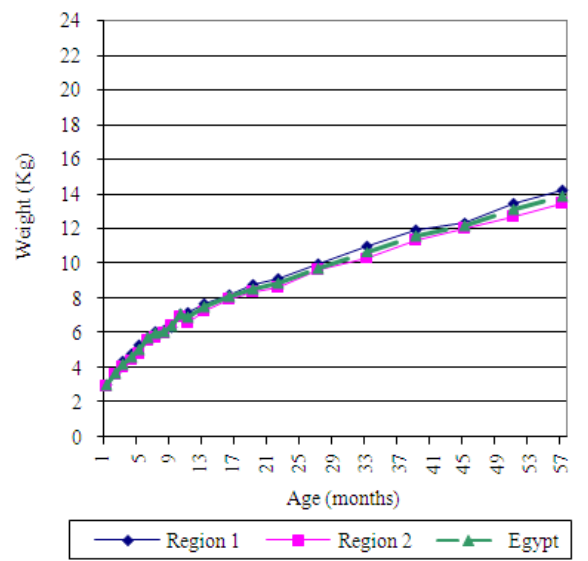

Fig. 3: 5th percentile curves for Egypt and the two regions

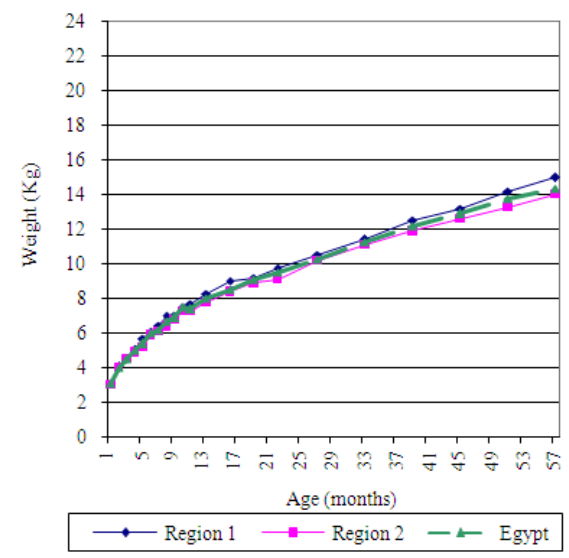

Fig. 4: 10th percentile curves for Egypt and the two regions 
Am. J. Biostatistics 1 (1): 46-61, 2010

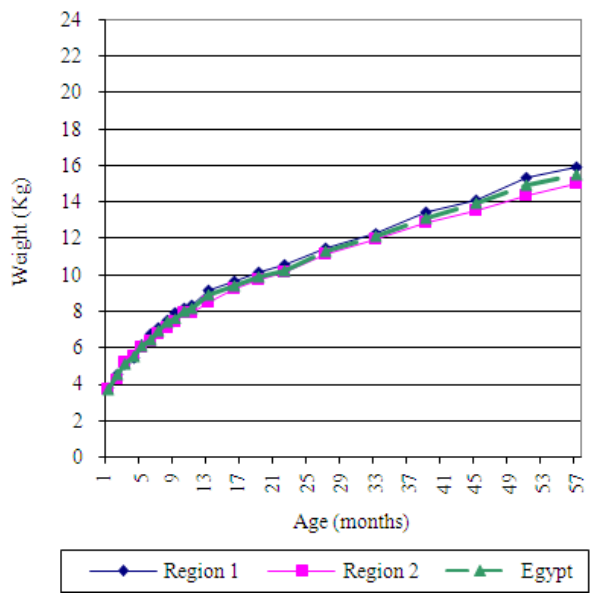

Fig. 5: 25th percentile curves for Egypt and the two regions

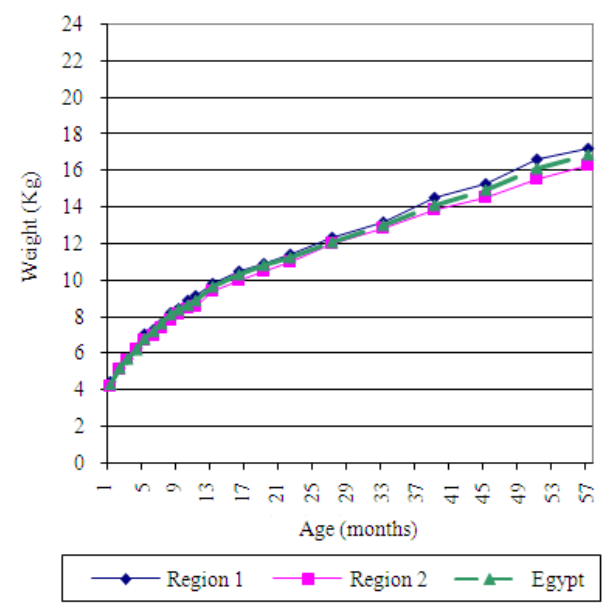

Fig. 6: 50th percentile curves for Egypt and the two regions

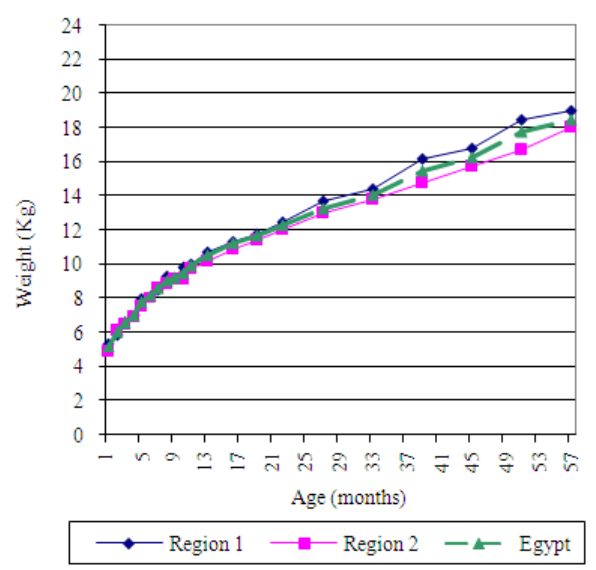

Fig. 7: 75th percentile curves for Egypt and the two regions

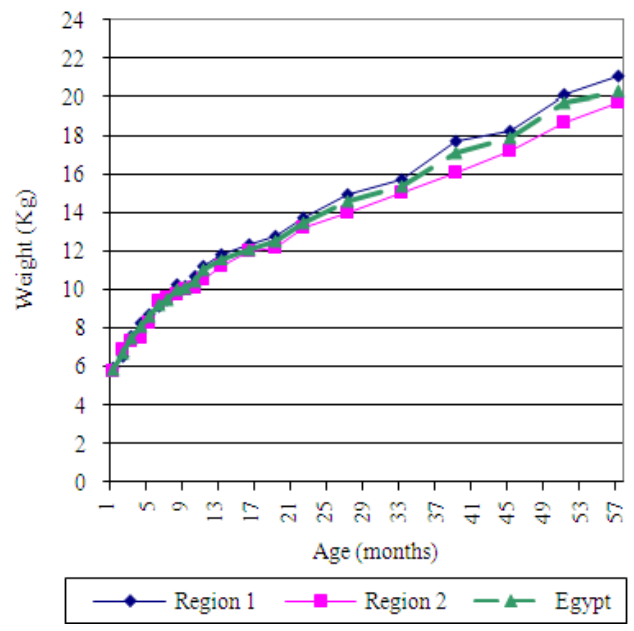

Fig. 8: 90th percentile curves for Egypt and the two regions

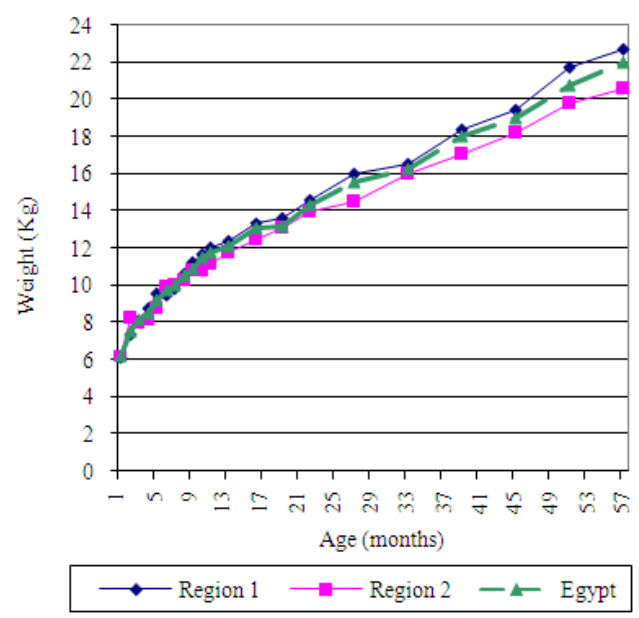

Fig. 9: 95th percentile curves for Egypt and the two regions

Testing the equality of the weight-for-age growth curves using the curve precedence test: Table 7-14 show the results of the curve precedence test used to test the equality of each pair of growth curves for Region 1 and 2.

The critical values of the $\chi^{2}$ distribution with $(\alpha=0.05)$ and number of groups $(L=21)$ are:

$$
\begin{aligned}
& \chi_{(0.975,21)}^{2}=10.283 \\
& \chi_{(0.025,21)}^{2}=35.479
\end{aligned}
$$

Comparing the calculated test statistics and $\chi^{2}$ tabulated values, we reject the hypothesis that each pair of percentile curves are equal (Table 14). 
Am. J. Biostatistics 1 (1): 46-61, 2010

Table 7: Results of the weight-for-age 5th percentile curve

\begin{tabular}{|c|c|c|c|c|}
\hline & $\begin{array}{l}\text { Urban } \\
\text { governorates } \\
\text { and lower } \\
\text { Egypt }(r)\end{array}$ & $\begin{array}{l}\text { Upper Egypt } \\
\text { and Frontier } \\
\text { governorates } \\
\left(\mathrm{p}_{(\mathrm{r})}\right)\end{array}$ & $E\left(p_{(r)}\right)$ & $\operatorname{Var}\left(\mathrm{p}_{(\mathrm{r})}\right)$ \\
\hline$\overline{1}$ & 18 & 23 & 13.36 & 21.86 \\
\hline 2 & 17 & 17 & 14.98 & 26.55 \\
\hline 3 & 14 & 17 & 10.83 & 18.17 \\
\hline 4 & 21 & 25 & 18.87 & 33.27 \\
\hline 5 & 12 & 26 & 11.77 & 22.15 \\
\hline 6 & 19 & 16 & 15.74 & 26.96 \\
\hline 7 & 16 & 25 & 13.26 & 22.78 \\
\hline 8 & 16 & 13 & 11.00 & 17.58 \\
\hline 9 & 14 & 11 & 12.44 & 22.25 \\
\hline 10 & 15 & 16 & 10.15 & 16.10 \\
\hline 11 & 17 & 21 & 13.97 & 23.73 \\
\hline $12-14$ & 45 & 54 & 34.87 & 58.44 \\
\hline $15-17$ & 45 & 54 & 35.08 & 59.10 \\
\hline $18-20$ & 42 & 52 & 32.30 & 54.31 \\
\hline $21-23$ & 43 & 59 & 30.35 & 49.04 \\
\hline $24-29$ & 88 & 93 & 63.47 & 103.78 \\
\hline $30-35$ & 81 & 114 & 65.70 & 113.02 \\
\hline $36-41$ & 83 & 137 & 68.41 & 118.45 \\
\hline $42-47$ & 82 & 103 & 66.39 & 113.89 \\
\hline $48-53$ & 87 & 154 & 67.69 & 113.90 \\
\hline $54-59$ & 73 & 152 & 58.75 & 100.63 \\
\hline
\end{tabular}

Table 8: Results of the weight-for-age 10th percentile curve precedence test

\begin{tabular}{|c|c|c|c|c|}
\hline & $\begin{array}{l}\text { Urban } \\
\text { governorates } \\
\text { and lower } \\
\text { Egypt (r) }\end{array}$ & $\begin{array}{l}\text { Upper Egypt } \\
\text { and Frontier } \\
\text { governorates } \\
\left(\mathrm{p}_{(\mathrm{r})}\right)\end{array}$ & $\mathrm{E}\left(\mathrm{p}_{(\mathrm{r})}\right)$ & $\operatorname{Var}\left(\mathrm{p}_{(\mathrm{r})}\right)$ \\
\hline 1 & 34 & 29 & 25.23 & 39.07 \\
\hline 2 & 30 & 32 & 26.43 & 44.78 \\
\hline 3 & 29 & 22 & 22.43 & 35.50 \\
\hline 4 & 42 & 44 & 37.75 & 61.63 \\
\hline 5 & 30 & 44 & 29.42 & 51.36 \\
\hline 6 & 38 & 51 & 31.49 & 50.47 \\
\hline 7 & 28 & 40 & 23.20 & 38.04 \\
\hline 8 & 33 & 55 & 22.69 & 34.23 \\
\hline 9 & 28 & 33 & 24.89 & 42.14 \\
\hline 10 & 30 & 30 & 20.31 & 30.44 \\
\hline 11 & 26 & 48 & 21.37 & 34.97 \\
\hline $12-14$ & 88 & 129 & 68.19 & 107.95 \\
\hline $15-17$ & 90 & 149 & 70.15 & 111.73 \\
\hline $18-20$ & 88 & 111 & 67.68 & 107.43 \\
\hline $21-23$ & 88 & 128 & 62.11 & 94.67 \\
\hline $24-29$ & 181 & 211 & 130.55 & 201.70 \\
\hline $30-35$ & 168 & 220 & 136.27 & 221.26 \\
\hline $36-41$ & 190 & 273 & 156.61 & 252.64 \\
\hline $42-47$ & 184 & 256 & 148.98 & 238.29 \\
\hline $48-53$ & 167 & 300 & 129.93 & 207.38 \\
\hline $54-59$ & 144 & 270 & 115.90 & 188.27 \\
\hline
\end{tabular}

Testing the equality of the weight-for-age growth curves using the curve chi-square test: Table 15 presents the results of the tests of the equality of the weight-for-age growth curves using the curve chisquare test.

$$
\begin{aligned}
& \sum_{\mathrm{j}=1}^{\mathrm{L}} \mathrm{V}_{\mathrm{j}} \text { has chi-square with } 21 \text { degrees of freedom } \\
& \chi_{(0.05,21)}^{2}=32.671 .
\end{aligned}
$$

Table 9: Results of the weight-for-age 25th percentile curve

\begin{tabular}{|c|c|c|c|c|}
\hline & $\begin{array}{l}\text { Urban } \\
\text { governorates } \\
\text { and lower } \\
\text { Egypt (r) }\end{array}$ & $\begin{array}{l}\text { Upper Egypt } \\
\text { and Frontier } \\
\text { governorates } \\
\left(\mathrm{p}_{(\mathrm{r})}\right)\end{array}$ & $\mathrm{E}\left(\mathrm{p}_{(\mathrm{r})}\right)$ & $\operatorname{Var}\left(\mathrm{p}_{(\mathrm{r})}\right)$ \\
\hline 1 & 81 & 76 & 60.11 & 77.45 \\
\hline 2 & 80 & 86 & 70.48 & 98.16 \\
\hline 3 & 75 & 49 & 58.00 & 74.84 \\
\hline 4 & 77 & 62 & 69.20 & 98.01 \\
\hline 5 & 71 & 94 & 69.63 & 99.88 \\
\hline 6 & 86 & 112 & 71.26 & 94.43 \\
\hline 7 & 79 & 100 & 65.46 & 85.62 \\
\hline 8 & 82 & 95 & 56.38 & 70.53 \\
\hline 9 & 79 & 107 & 70.22 & 94.74 \\
\hline 10 & 77 & 69 & 52.13 & 64.07 \\
\hline 11 & 75 & 97 & 61.65 & 80.11 \\
\hline $12-14$ & 224 & 268 & 173.59 & 223.87 \\
\hline $15-17$ & 229 & 260 & 178.49 & 233.36 \\
\hline $18-20$ & 235 & 252 & 180.73 & 232.69 \\
\hline $21-23$ & 212 & 237 & 149.62 & 190.26 \\
\hline $24-29$ & 483 & 454 & 348.38 & 436.33 \\
\hline $30-35$ & 436 & 504 & 353.67 & 469.03 \\
\hline $36-41$ & 430 & 570 & 354.42 & 477.77 \\
\hline $42-47$ & 399 & 500 & 323.06 & 437.83 \\
\hline $48-53$ & 453 & 616 & 352.46 & 453.31 \\
\hline $54-59$ & 377 & 489 & 303.42 & 404.96 \\
\hline
\end{tabular}
precedence test

Table 10: Results of the weight-for-age 50th percentile curve

\begin{tabular}{|c|c|c|c|c|}
\hline & $\begin{array}{l}\text { Urban } \\
\text { governorates } \\
\text { and lower } \\
\text { Egypt (r) }\end{array}$ & $\begin{array}{l}\text { Upper Egypt } \\
\text { and Frontier } \\
\text { governorates } \\
\left(\mathrm{p}_{(\mathrm{r})}\right)\end{array}$ & $\mathrm{E}\left(\mathrm{p}_{(\mathrm{r})}\right)$ & $\operatorname{Var}\left(\mathrm{p}_{(\mathrm{r})}\right)$ \\
\hline 1 & 157 & 139 & 116.50 & 101.15 \\
\hline 2 & 160 & 154 & 140.96 & 128.33 \\
\hline 3 & 148 & 108 & 114.46 & 94.58 \\
\hline 4 & 166 & 150 & 149.18 & 129.17 \\
\hline 5 & 136 & 154 & 133.38 & 125.52 \\
\hline 6 & 161 & 166 & 133.40 & 118.88 \\
\hline 7 & 141 & 133 & 116.83 & 105.67 \\
\hline 8 & 161 & 136 & 110.69 & 92.52 \\
\hline 9 & 147 & 157 & 130.67 & 116.36 \\
\hline 10 & 150 & 134 & 101.55 & 82.23 \\
\hline 11 & 138 & 139 & 113.43 & 98.27 \\
\hline $12-14$ & 430 & 407 & 333.22 & 281.71 \\
\hline $15-17$ & 452 & 441 & 352.31 & 299.36 \\
\hline $18-20$ & 437 & 421 & 336.08 & 294.18 \\
\hline $21-23$ & 432 & 382 & 304.88 & 251.01 \\
\hline $24-29$ & 913 & 796 & 658.53 & 550.49 \\
\hline $30-35$ & 846 & 826 & 686.24 & 597.84 \\
\hline $36-41$ & 839 & 962 & 691.54 & 619.69 \\
\hline $42-47$ & 817 & 879 & 661.50 & 582.40 \\
\hline $48-53$ & 821 & 926 & 638.78 & 566.85 \\
\hline $54-59$ & 748 & 781 & 602.01 & 525.67 \\
\hline
\end{tabular}
precedence test

Comparing the calculated test statistics and $\chi^{2}$ tabulated values, we reject the hypothesis that each pair of percentile curves is equal except for the 95th percentile curves. 
Am. J. Biostatistics 1 (1): 46-61, 2010

Table 11: Results of the weight-for-age 75th percentile curve precedence test

\begin{tabular}{|c|c|c|c|c|}
\hline & $\begin{array}{l}\text { Urban } \\
\text { governorates } \\
\text { and lower } \\
\text { Egypt }(r)\end{array}$ & $\begin{array}{l}\text { Upper Egypt } \\
\text { and Frontier } \\
\text { governorates } \\
\left(\mathrm{p}_{(\mathrm{r})}\right)\end{array}$ & $\mathrm{E}\left(\mathrm{p}_{(\mathrm{r})}\right)$ & $\operatorname{Var}\left(\mathrm{p}_{(\mathrm{r})}\right)$ \\
\hline 1 & 243 & 199 & 180.32 & 70.80 \\
\hline 2 & 237 & 197 & 208.80 & 93.16 \\
\hline 3 & 213 & 169 & 164.73 & 68.06 \\
\hline 4 & 229 & 212 & 205.80 & 98.01 \\
\hline 5 & 195 & 221 & 191.25 & 94.34 \\
\hline 6 & 237 & 201 & 196.37 & 88.63 \\
\hline 7 & 210 & 172 & 174.00 & 79.26 \\
\hline 8 & 243 & 190 & 167.06 & 67.63 \\
\hline 9 & 211 & 194 & 187.56 & 86.04 \\
\hline 10 & 221 & 171 & 149.61 & 60.15 \\
\hline 11 & 204 & 173 & 167.68 & 69.17 \\
\hline $12-14$ & 623 & 536 & 482.79 & 207.20 \\
\hline $15-17$ & 653 & 566 & 508.98 & 222.51 \\
\hline $18-20$ & 650 & 553 & 499.88 & 220.32 \\
\hline $21-23$ & 642 & 491 & 453.09 & 179.13 \\
\hline $24-29$ & 1359 & 1132 & 980.22 & 395.94 \\
\hline $30-35$ & 1231 & 1124 & 998.54 & 443.26 \\
\hline $36-41$ & 1259 & 1235 & 1037.72 & 448.32 \\
\hline $42-47$ & 1201 & 1128 & 972.42 & 431.93 \\
\hline $48-53$ & 1249 & 1145 & 971.78 & 411.70 \\
\hline $54-59$ & 1093 & 983 & 879.68 & 390.62 \\
\hline
\end{tabular}

Table 12: Results of the weight-for-age 90th percentile curve precedence test

\begin{tabular}{|c|c|c|c|c|}
\hline & $\begin{array}{l}\text { Urban } \\
\text { Governorates } \\
\text { and lower } \\
\text { Egypt ( r ) }\end{array}$ & $\begin{array}{l}\text { Upper Egypt } \\
\text { and Frontier } \\
\text { governorates } \\
\left(\mathrm{p}_{(\mathrm{r})}\right)\end{array}$ & $\mathrm{E}\left(\mathrm{p}_{(\mathrm{r})}\right)$ & $\operatorname{Var}\left(\mathrm{p}_{(\mathrm{r})}\right)$ \\
\hline 1 & 284 & 213 & 210.74 & 34.96 \\
\hline 2 & 283 & 233 & 249.33 & 42.09 \\
\hline 3 & 251 & 198 & 194.12 & 33.31 \\
\hline 4 & 278 & 266 & 249.84 & 43.26 \\
\hline 5 & 233 & 242 & 228.52 & 46.83 \\
\hline 6 & 286 & 228 & 236.97 & 39.77 \\
\hline 7 & 251 & 204 & 207.97 & 39.25 \\
\hline 8 & 287 & 210 & 197.31 & 34.23 \\
\hline 9 & 251 & 230 & 223.11 & 42.14 \\
\hline 10 & 262 & 187 & 177.37 & 29.54 \\
\hline 11 & 241 & 208 & 198.09 & 31.33 \\
\hline $12-14$ & 746 & 607 & 578.10 & 94.76 \\
\hline $15-17$ & 782 & 637 & 609.53 & 105.08 \\
\hline $18-20$ & 783 & 628 & 602.17 & 101.98 \\
\hline $21-23$ & 756 & 551 & 533.54 & 86.99 \\
\hline $24-29$ & 1599 & 1233 & 1153.33 & 197.74 \\
\hline $30-35$ & 1472 & 1244 & 1194.03 & 210.69 \\
\hline $36-41$ & 1488 & 1326 & 1226.47 & 219.54 \\
\hline $42-47$ & 1437 & 1226 & 1163.50 & 204.87 \\
\hline $48-53$ & 1479 & 1232 & 1150.73 & 200.74 \\
\hline 54-59 & 1306 & 1120 & 1051.10 & 188.27 \\
\hline
\end{tabular}

Testing the equality of the two sets of weight-forage growth curves using the curves set chi-square test: Table 16 shows the results of the curves set chisquare test. V has chi-square with $147^{\circ}$ of freedom $\chi_{(0.05,147)}^{2}=176.29$.
Table 13: Results of the weight-for-age 95th percentile curve precedence test

\begin{tabular}{|c|c|c|c|c|}
\hline & $\begin{array}{l}\text { Urban } \\
\text { governorates } \\
\text { and lower } \\
\text { Egypt (r) }\end{array}$ & $\begin{array}{l}\text { Upper Egypt } \\
\text { and Frontier } \\
\text { governorates } \\
\left(\mathrm{p}_{(\mathrm{r})}\right)\end{array}$ & $\mathrm{E}\left(\mathrm{p}_{(\mathrm{r})}\right)$ & $\operatorname{Var}\left(\mathrm{p}_{(\mathrm{r})}\right)$ \\
\hline 1 & 298 & 219 & 221.13 & 19.57 \\
\hline 2 & 295 & 255 & 259.9 & 25.07 \\
\hline 3 & 267 & 206 & 206.49 & 14.44 \\
\hline 4 & 291 & 268 & 261.52 & 24.26 \\
\hline 5 & 249 & 252 & 244.21 & 20.39 \\
\hline 6 & 299 & 241 & 247.74 & 22.94 \\
\hline 7 & 265 & 218 & 219.57 & 21.43 \\
\hline 8 & 305 & 213 & 209.69 & 16.53 \\
\hline 9 & 265 & 243 & 235.56 & 22.25 \\
\hline 10 & 277 & 191 & 187.52 & 15.08 \\
\hline 11 & 252 & 210 & 207.14 & 17.09 \\
\hline $12-14$ & 780 & 616 & 604.45 & 54.75 \\
\hline $15-17$ & 824 & 655 & 642.26 & 55.36 \\
\hline $18-20$ & 822 & 649 & 632.16 & 56.75 \\
\hline $21-23$ & 796 & 575 & 561.77 & 45.79 \\
\hline $24-29$ & 1694 & 1253 & 1221.85 & 97.05 \\
\hline $30-35$ & 1557 & 1285 & 1262.97 & 103.72 \\
\hline $36-41$ & 1574 & 1342 & 1297.36 & 108.95 \\
\hline $42-47$ & 1513 & 1256 & 1225.04 & 109.94 \\
\hline $48-53$ & 1560 & 1259 & 1213.76 & 105.21 \\
\hline $54-59$ & 1378 & 1153 & 1109.05 & 99.32 \\
\hline
\end{tabular}

Table 14: Results of the weight-for-age growth curves precedence test

\begin{tabular}{lll}
\hline Percentile & $\mathrm{V}_{\mathrm{r}}$ & Decision $(\alpha=0.05)$ \\
\hline 5 & 295.89 & Reject $\mathrm{H}_{0}$ \\
10 & 660.52 & Reject $\mathrm{H}_{0}$ \\
25 & 711.30 & Reject $\mathrm{H}_{0}$ \\
50 & 620.48 & Reject $\mathrm{H}_{0}$ \\
75 & 418.90 & Reject $\mathrm{H}_{0}$ \\
90 & 223.67 & Reject $\mathrm{H}_{0}$ \\
95 & 107.22 & Reject $\mathrm{H}_{0}$ \\
\hline
\end{tabular}

Table 15: Results of the weight-for-age growth curves chi-square test

\begin{tabular}{lcl}
\hline Percentile & $\sum_{\mathrm{j}=1}^{\mathrm{L}} \mathrm{V}_{\mathrm{j}}$ & Decision $(\alpha=0.05)$ \\
\hline 05 & 150.72 & Reject $\mathrm{H}_{0}$ \\
10 & 304.95 & Reject $\mathrm{H}_{0}$ \\
25 & 435.08 & Reject $\mathrm{H}_{0}$ \\
50 & 327.08 & Reject $\mathrm{H}_{0}$ \\
75 & 141.32 & Reject $\mathrm{H}_{0}$ \\
90 & 35.37 & Reject $\mathrm{H}_{0}$ \\
95 & 8.82 & Can't reject $\mathrm{H}_{0}$ \\
\hline
\end{tabular}

Comparing the calculated test statistic and $\chi^{2}$ tabulated value, we reject the hypothesis that the two sets of curves are equal. 
Am. J. Biostatistics 1 (1): 46-61, 2010

Table 16: Results of the weight-for-age curves set chi-square test

\begin{tabular}{|c|c|c|c|c|c|c|c|c|c|}
\hline \multirow[b]{2}{*}{ Age group } & \multicolumn{8}{|l|}{ Percentile } & \multirow[b]{2}{*}{ Total } \\
\hline & & p05 & p10 & p25 & $\mathrm{p} 50$ & p75 & $\mathrm{p} 90$ & p95 & \\
\hline \multirow[t]{5}{*}{1} & $\mathrm{O}_{1}$ & 18.00 & 15.00 & 40.00 & 76.00 & 80.00 & 51.00 & 21.00 & \\
\hline & $\mathrm{O}_{2}$ & 23.00 & 6.00 & 35.00 & 69.00 & 61.00 & 17.00 & 10.00 & \\
\hline & e1 & 23.50 & 12.04 & 42.99 & 83.12 & 80.83 & 38.98 & 17.77 & \\
\hline & $\mathrm{e} 2$ & 17.50 & 8.96 & 32.01 & 61.88 & 60.17 & 29.02 & 13.23 & \\
\hline & Chi-square & 3.02 & 1.71 & 0.49 & 1.43 & 0.02 & 8.68 & 1.37 & 16.72 \\
\hline \multirow[t]{5}{*}{2} & $\mathrm{O}_{1}$ & 17.00 & 13.00 & 50.00 & 80.00 & 85.00 & 40.00 & 14.00 & \\
\hline & $\mathrm{O}_{2}$ & 17.00 & 15.00 & 53.00 & 68.00 & 50.00 & 39.00 & 15.00 & \\
\hline & e1 & 18.05 & 14.86 & 54.67 & 78.56 & 71.66 & 41.93 & 15.39 & \\
\hline & e2 & 15.95 & 13.14 & 48.33 & 69.44 & 63.34 & 37.07 & 13.61 & \\
\hline & Chi-square & 0.13 & 0.50 & 0.85 & 0.06 & 5.29 & 0.19 & 0.27 & 7.29 \\
\hline \multirow[t]{5}{*}{3} & $\mathrm{O}_{1}$ & 12.00 & 16.00 & 46.00 & 73.00 & 59.00 & 43.00 & 18.00 & \\
\hline & $\mathrm{O}_{2}$ & 14.00 & 7.00 & 27.00 & 59.00 & 57.00 & 33.00 & 9.00 & \\
\hline & e1 & 14.64 & 12.95 & 41.10 & 74.32 & 65.31 & 42.79 & 15.20 & \\
\hline & e2 & 11.36 & 10.05 & 31.90 & 57.68 & 50.69 & 33.21 & 11.80 & \\
\hline & Chi-square & 1.09 & 1.64 & 1.34 & 0.05 & 1.39 & 0.00 & 1.18 & 6.70 \\
\hline \multirow[t]{5}{*}{4} & $\mathrm{O}_{1}$ & 13.00 & 13.00 & 59.00 & 66.00 & 77.00 & 43.00 & 13.00 & \\
\hline & $\mathrm{O}_{2}$ & 18.00 & 16.00 & 36.00 & 72.00 & 70.00 & 48.00 & 7.00 & \\
\hline & e1 & 16.30 & 15.25 & 49.96 & 72.57 & 77.30 & 47.85 & 10.52 & \\
\hline & e2 & 14.70 & 13.75 & 45.04 & 65.43 & 69.70 & 43.15 & 9.48 & \\
\hline & Chi-square & 1.41 & 0.70 & 3.45 & 1.25 & 0.00 & 1.04 & 1.24 & 9.09 \\
\hline \multirow[t]{5}{*}{5} & $\mathrm{O}_{1}$ & 10.00 & 6.00 & 43.00 & 63.00 & 62.00 & 42.00 & 16.00 & \\
\hline & $\mathrm{O}_{2}$ & 15.00 & 22.00 & 46.00 & 61.00 & 65.00 & 31.00 & 8.00 & \\
\hline & $\mathrm{e} 1$ & 12.60 & 14.11 & 44.85 & 62.48 & 63.99 & 36.78 & 12.09 & \\
\hline & $\mathrm{e} 2$ & 12.40 & 13.89 & 44.15 & 61.52 & 63.01 & 36.22 & 11.91 & \\
\hline & Chi-square & 1.08 & 9.39 & 0.15 & 0.01 & 0.13 & 1.49 & 2.54 & 14.80 \\
\hline \multirow[t]{5}{*}{6} & $\mathrm{O}_{1}$ & 19.00 & 8.00 & 38.00 & 82.00 & 90.00 & 54.00 & 13.00 & \\
\hline & $\mathrm{O}_{2}$ & 16.00 & 20.00 & 52.00 & 70.00 & 43.00 & 31.00 & 12.00 & \\
\hline & e1 & 19.11 & 15.29 & 49.15 & 83.01 & 72.63 & 46.42 & 13.65 & \\
\hline & e2 & 15.89 & 12.71 & 40.85 & 68.99 & 60.37 & 38.58 & 11.35 & \\
\hline & Chi-square & 0.00 & 7.66 & 5.57 & 0.03 & 9.15 & 2.73 & 0.07 & 25.21 \\
\hline \multirow[t]{5}{*}{7} & $\mathrm{O}_{1}$ & 7.00 & 13.00 & 42.00 & 78.00 & 74.00 & 45.00 & 8.00 & \\
\hline & $\mathrm{O}_{2}$ & 18.00 & 14.00 & 46.00 & 55.00 & 42.00 & 35.00 & 13.00 & \\
\hline & e1 & 13.65 & 14.74 & 48.05 & 72.62 & 63.33 & 43.68 & 11.47 & \\
\hline & e2 & 11.35 & 12.26 & 39.95 & 60.38 & 52.67 & 36.32 & 9.53 & \\
\hline & Chi-square & 7.14 & 0.45 & 1.68 & 0.88 & 3.96 & 0.09 & 2.31 & 16.50 \\
\hline \multirow[t]{5}{*}{8} & $\mathrm{O}_{1}$ & 14.00 & 12.00 & 43.00 & 80.00 & 83.00 & 49.00 & 20.00 & \\
\hline & $\mathrm{O}_{2}$ & 12.00 & 22.00 & 55.00 & 41.00 & 44.00 & 35.00 & 5.00 & \\
\hline & e1 & 15.39 & 20.12 & 58.00 & 71.61 & 75.16 & 49.71 & 14.80 & \\
\hline & $\mathrm{e} 2$ & 10.61 & 13.88 & 40.00 & 49.39 & 51.84 & 34.29 & 10.20 & \\
\hline & Chi-square & 0.31 & 8.03 & 9.50 & 2.41 & 2.00 & 0.03 & 4.48 & 26.76 \\
\hline \multirow[t]{5}{*}{9} & $\mathrm{O}_{1}$ & 16.00 & 8.00 & 36.00 & 74.00 & 77.00 & 35.00 & 14.00 & \\
\hline & $\mathrm{O}_{2}$ & 13.00 & 16.00 & 52.00 & 64.00 & 49.00 & 35.00 & 12.00 & \\
\hline & e1 & 15.33 & 12.68 & 46.51 & 72.94 & 66.59 & 37.00 & 13.74 & \\
\hline & $\mathrm{e} 2$ & 13.67 & 11.32 & 41.49 & 65.06 & 59.41 & 33.00 & 12.26 & \\
\hline & Chi-square & 0.06 & 3.67 & 5.04 & 0.03 & 3.45 & 0.23 & 0.01 & 12.49 \\
\hline 10 & $\mathrm{O}_{1}$ & 15.00 & 15.00 & 34.00 & 65.00 & 79.00 & 46.00 & 19.00 & \\
\hline & $\mathrm{O}_{2}$ & 16.00 & 14.00 & 28.00 & 56.00 & 53.00 & 19.00 & 4.00 & \\
\hline & e1 & 18.46 & 17.27 & 36.92 & 72.05 & 78.60 & 38.71 & 13.70 & \\
\hline & $\mathrm{e} 2$ & 12.54 & 11.73 & 25.08 & 48.95 & 53.40 & 26.29 & 9.30 & \\
\hline & Chi-square & 1.60 & 0.74 & 0.57 & 1.71 & 0.00 & 3.40 & 5.08 & 13.10 \\
\hline 11 & $\mathrm{O}_{1}$ & 11.00 & 9.00 & 31.00 & 77.00 & 63.00 & 39.00 & 16.00 & \\
\hline & $\mathrm{O}_{2}$ & 15.00 & 20.00 & 45.00 & 47.00 & 42.00 & 35.00 & 5.00 & \\
\hline & e1 & 14.25 & 15.89 & 41.64 & 67.94 & 57.53 & 40.55 & 11.51 & \\
\hline & e2 & 11.75 & 13.11 & 34.36 & 56.06 & 47.47 & 33.45 & 9.49 & \\
\hline & Chi-square & 1.64 & 6.61 & 6.02 & 2.67 & 1.15 & 0.13 & 3.88 & 22.09 \\
\hline $12-14$ & $\mathrm{O}_{1}$ & 37.00 & 20.00 & 123.00 & 202.00 & 213.00 & 123.00 & 59.00 & \\
\hline & $\mathrm{O}_{2}$ & 44.00 & 45.00 & 133.00 & 153.00 & 149.00 & 75.00 & 13.00 & \\
\hline & $\mathrm{e} 1$ & 45.61 & 36.60 & 144.15 & 199.90 & 203.84 & 111.49 & 40.54 & \\
\hline & e2 & 35.39 & 28.40 & 111.85 & 155.10 & 158.16 & 86.51 & 31.46 & \\
\hline & Chi-square & 3.72 & 17.24 & 7.10 & 0.05 & 0.94 & 2.72 & 19.23 & 51.00 \\
\hline $15-17$ & $\mathrm{O}_{1}$ & 40.00 & 24.00 & 133.00 & 205.00 & 221.00 & 145.00 & 47.00 & \\
\hline & $\mathrm{O}_{2}$ & 44.00 & 47.00 & 127.00 & 193.00 & 150.00 & 73.00 & 17.00 & \\
\hline
\end{tabular}


Am. J. Biostatistics 1 (1): 46-61, 2010

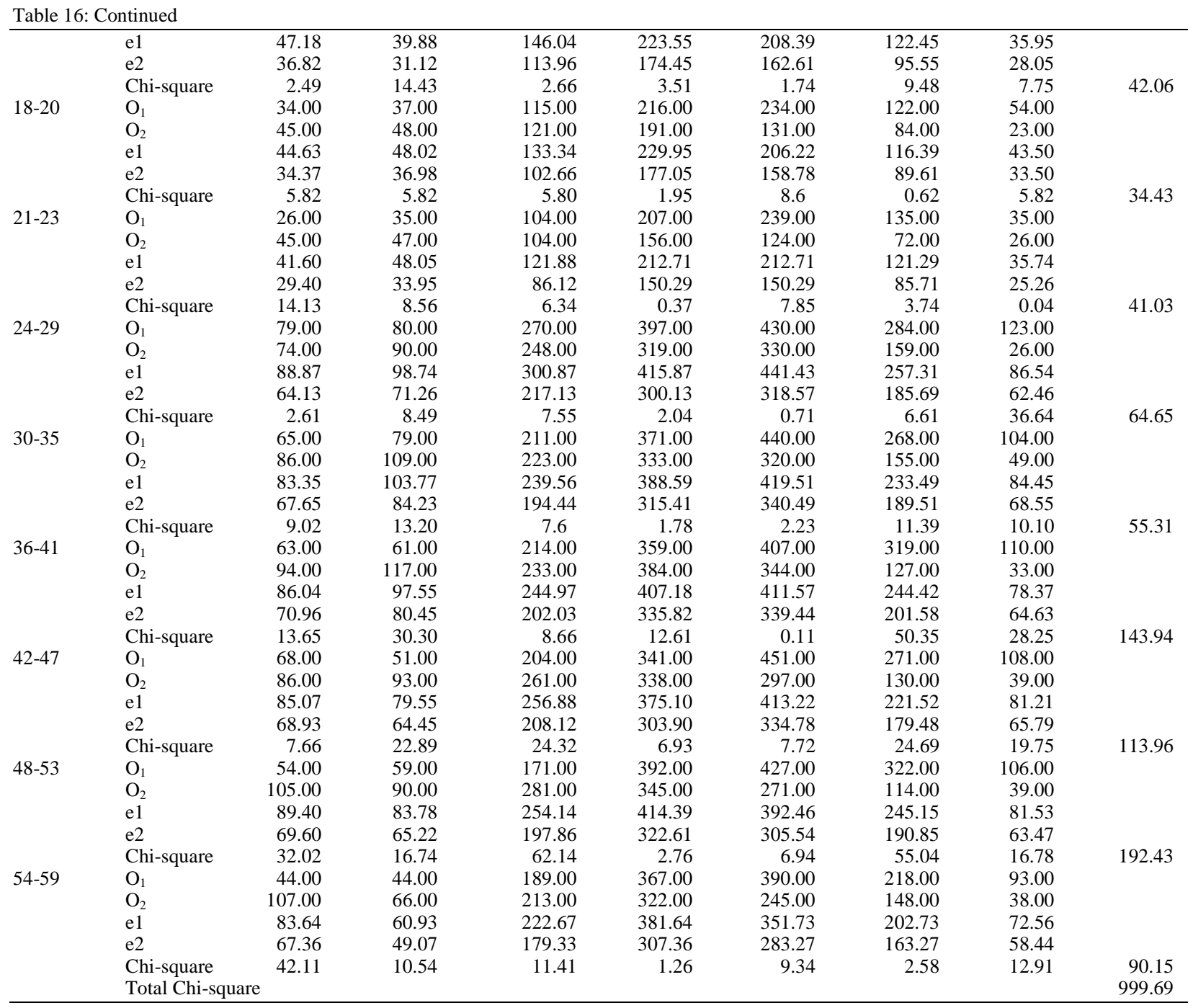

\section{CONCLUSION}

The powers of the tests were estimated in the case of symmetric distributions applied to the normal distribution and in the case of skewed distribution applied to the Gamma distribution. The curve precedence test was more powerful than the curve chisquare test in testing the equality of growth curves under the shift in the location parameter of both the normal distribution and the gamma distribution. It was also more powerful than the curve chi-square test in testing the equality of growth curves under the shift in the scale parameter of the gamma distribution and in testing equality of growth curves with high ranks under the shift in the scale parameter of the normal distribution. Table 17 shows the preferred test in selected cases.
Table 17: Preferred test in selected cases

\begin{tabular}{llll}
\hline Shift & Percentile & Normal Dist. & Gamma Dist. \\
\hline Location parameter & Any & Curve precedence & Curve precedence \\
Scale & 10th & Curve chi-square & Curve precedence \\
Parameter & 75th & Curve precedence & Curve precedence \\
\hline
\end{tabular}

Applying the new tests to the weight-for-age growth curves of the two Egyptian regions showed that the regions have different growth curves and hence different nutritional status.

\section{REFERENCES}

Ashour, S.K. and S.A. Salem, 2005. Probability Distributions. Institute of Statistical Studies and Research (ISSR), Cairo University, pp: 197-202. 
Balakrishnan, N. and H.K. Tony Ng, 2006. PrecedenceType Tests and Applications. John Wiley and Sons, New Jersey, pp: 31-40.

Desu, M.M. and D. Raghavarao, 2004. Nonparametric Statistical Methods for Complete and Censored Data. Chapman and Hall/CRC, pp: 76-82.

Dibley, M.J., N.W. Staehling, P. Nieburg and F.L. Trowbridge, 1987a. Interpretation of Z-score anthropometric indicators derived from the international growth reference. Am. J. Clin. Nutr., 46: 749-762.

Dibley, M.J., J.B. Goldsby, N.W. Staehling and F.L. Trowbridge, 1987b. Development of normalized curves for the international growth curves: Historical and technical considerations. Am. J. Clin. Nutr., 46: 736-748.
Kapur, J.N. and H.C. Saxena, 2007. Mathematical Statistics. 20th Edn., S. Chand and Company LTD., New Delhi, pp: 591-598.

Kuczmarski, R.J. C.L. Ogden, S.S. Guo, L.M.G. Strawn and K.M. Flegal et al., 2002. 2000 CDC Growth charts for united states: Methods and development. Vital Health Stat., 246: 1-18.

Matthews, B., M. Billiet and A. Borrell, 2000. The Practical Implications of Using Z-Scores: Concern's Experience in Angola. Emergency Nutrition Network.

http://www.ennonline.net/fex/01/fa6.html 